\title{
The Prevalence of Anterior Teeth Fracture and its Relation to Malocclusion in 12 and 15 Year Old School Children Belgaum City India
}

\section{Pradeep S Tangade}

\section{ABSTRACT}

The objectives of this study were to know the prevalence of anterior teeth fracture and malocclusion and their correlation among the school going children aged 12 and 15 years, as well as to analyze the general relative risk factors like age, sex, malocclusion, nature and place of trauma.

Method: an epidemiological cross sectional study was carried out among 3621 school going children (2418 boys and 1203 girls) in Belgaum city aged 12 and 15 years. Interview was conducted fro other variables and clinical examination using modified WHO performa was done.

Results: The prevalence of anterior teeth fracture was $4.41 \%$. The prevalence rate for males was $4.96 \%$ and females 3.33\%. The maxillary left central incisor had more risk for fracture (42.7\%). Enamel fractures compromised of $59.54 \%$. The prevalence rate of malocclusion was $27.3 \%$.

Conclusions: the study concludes that there is a strong relationship between malocclusion and fractured anterior teeth $(p<0.001)$.

Key words: Malocclusion, Trauma, Prevalence, Tooth Fracture

Key words: Referral, periodontics, periodontology, periodontitis, consultation, dental college, consumerism.

\section{Contact Author}

Dr. Pradeep. S.Tangade

E-mail: pradeeptangade@yahoo.co.in
$\mathrm{M}$ an, throughout his evolutionary advancement, has been subjected constantly to environment. Some changes were beneficial and others detrimental to his well being. Trauma to anterior teeth is undesirable and prevention of this is beneficial to the personality development of the child. Dental injuries may occur throughout life, but they are particularly common in childhood.

The problem of fractured anterior teeth is a perplexing one to the parent, child and especially the dentist. The behavior of child, as well as his progress in school and especially his psychological stability, could be affected by an untreated and unsightly fracture of an anterior tooth.(1)

During childhood,the development of the occlusion both functionally and esthetically is dependent on the satisfactory presence of the teeth. Hence, a traumatized region if ignored will result in malformed or malpositioned teeth. Dental injuries are infrequent during the first year of life, but can occur, for example due to a fall from a baby carriage. Injuries increase substantially with the child's first effort to move about. The frequency increases as the child begins to walk and run due to lack of experience and coordination. The incidence of dental injuries reaches its peak just before school age and consists mainly of injuries due to falls and collisions. When the child reaches school age, accidents in the playground are very common.(2) A major predisposing factor for dental injuries is increased over jet.(3) The dental injuries are twice more frequent among children with protruding incisors than children with normal occlusion.(4) The dentist is instrumental in 
preventing malocclusion and fractures of anterior teeth and hence improves one's personality and self-esteem. Hence a study was carried out with the aim to find out the prevalence of anterior teeth fracture and to correlate with malocclusion among school children of Belgaum city, aged 12 and 15 years. The objectives were to know the prevalence of anterior teeth fracture and to correlate with the general relative risk factors like age, sex, nature and place of trauma.

\section{MATERIALS AND METHODS}

The present study was carried out at Belgaum city on 3621 school children (2418 boys and 1203 girls) for a period of two months. Belgaum is one of the oldest towns of Karnataka in India. It is situated in northwest region of Karnataka with area

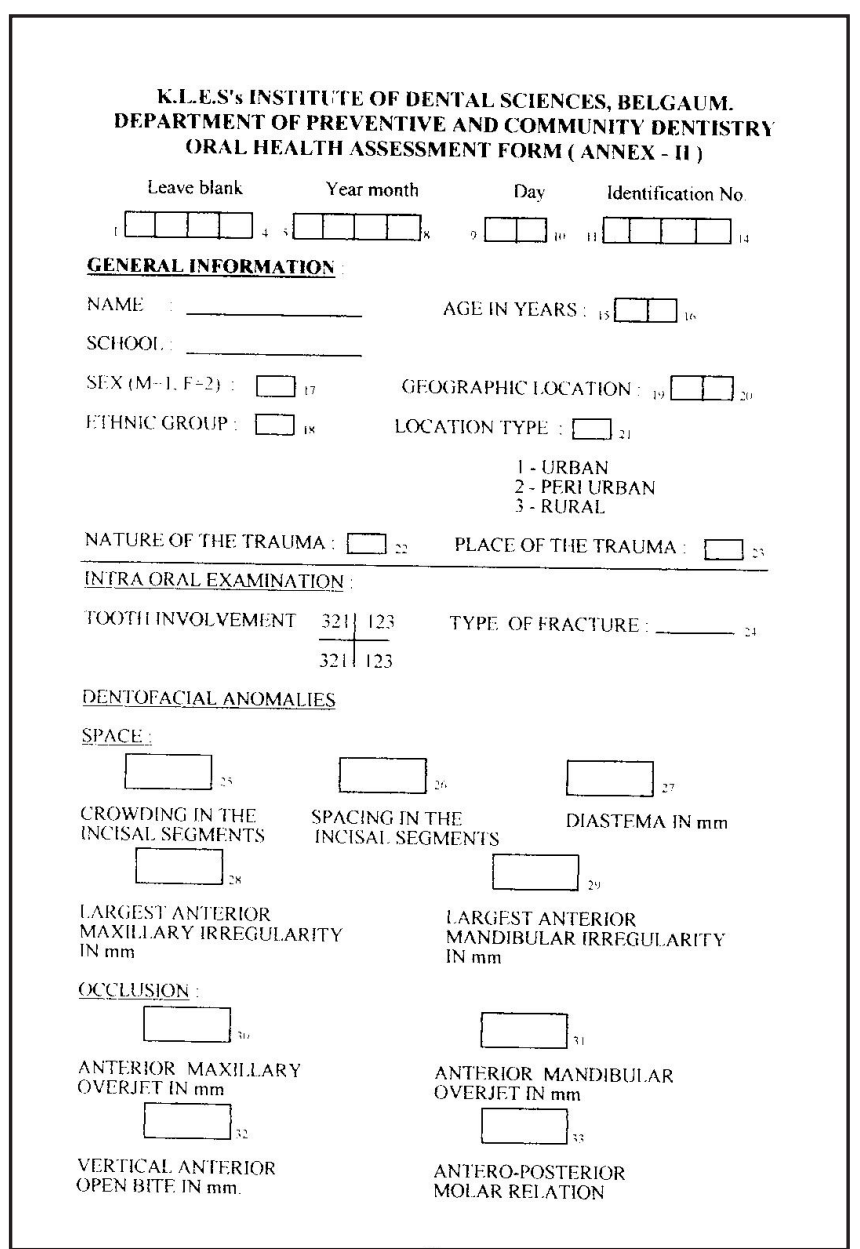

of 72 square kilometers, with population as per 1991 census being four lakhs. People from different religious, socio economic background, culture and habits reside in the city.

The consent was obtained from the concerned authorities of education department, schools, parents and approval for the study was obtained from the KLE'S Research and Ethical Committee, Belgaum. Data was collected by an interview and oral examination. The children attending primary/secondary school in Belgaum city and who had entered $12^{\text {th }}$ or $15^{\text {th }}$ year on their last birthday were included in this study. Children who were undergoing or had finished orthodontic treatment were excluded from the study. Out of total 36 secondary schools in the city, 11 were selected by simple random sampling giving equal importance to all the four areas (for study purpose, Belgaum city map was divided into four quadrants). A Type III oral clinical examination was done.(5) One examiner with the help of an alert and co-operative recording clerk carried out the examination and interview. Anterior teeth fracture was assessed according to W.H.O classification; the six maxillary and mandibular teeth were examined.(6) The WHO basic survey method(7) was modified and used for scoring dentofacial anomalies like malocclusion (box 25-33), nature of trauma (box 22), and place of trauma (box 23).

Data obtained was subjected to statistical analysis using Z Proportionality test and chi-square test (confidence interval $95 \%)$.

The oral health assessment form (modified WHO) used in study

\section{RESULTS}

The table I shows the prevalence rate of injury to anterior teeth fracture being $4.41 \%$. The prevalence of fracture in males (4.96) was more than females (3.33) which was significant $(\mathrm{Z}=2.25, \mathrm{p}<0.05)$. The ratio of prevalence between male and female was 1:0.5. It was observed that 12-year group had more fractures $7.14 \%$ when compared to 15 -year age group $5.03 \%$. Central incisor $83.2 \%$ (i.e., maxillary right $42.7 \%$ and $40.4 \%$ left central incisor) were more commonly fractured and least affected were the canines $1.8 \%$ (maxillary left canine $0.5 \%$ ). Single tooth fracture was more common $(62.5 \%)$ than two teeth fractures $(37.5 \%)$. Table II shows that $59.54 \%$ were enamel fractures, $32.73 \%$ were crown fracture without pulp

Table 1: Prevalence of anterior teeth fracture

\begin{tabular}{|c|c|c|c|c|c|c|}
\hline Sex & $\begin{array}{l}\text { No. of children } \\
\text { examined }\end{array}$ & $\begin{array}{l}\text { No. of children } \\
\text { with fractured } \\
\text { anterior teeth }\end{array}$ & $\begin{array}{l}\% \text { of } t \\
\text { in a }\end{array}$ & $\begin{array}{l}\text { tures } \\
\text { ps }\end{array}$ & $\begin{array}{l}\% \text { of children } \\
\text { with fractured } \\
\text { anterior teeth }\end{array}$ & Prevalence \\
\hline MALE & $241866.8 \%$ & $12075 \%$ & 7.5 & 6.3 & $3.31 \%$ & 4.96 \\
\hline FEMALE & $120333.22 \%$ & $4025 \%$ & 5.06 & 4.06 & $1.10 \%$ & 3.33 \\
\hline TOTAL & 3621 & 160 & & & $4.41 \%$ & $Z$ score $=2.25 \mathrm{P}<0.05$ \\
\hline
\end{tabular}


Table 2: Fractures classified according to WHO

\begin{tabular}{llcc}
$\begin{array}{l}\text { Type of } \\
\text { Fracture }\end{array}$ & $\begin{array}{c}\text { No. of Fractured } \\
\text { Teeth }\end{array}$ & $\%$ \\
\hline Code & Type & 131 & 59.54 \\
873.60 & Enamel fracture & 72 & 32.73 \\
873.61 & $\begin{array}{l}\text { Crown fracture without } \\
\text { pulp involvement }\end{array}$ & 17 & 7.73 \\
873.62 & $\begin{array}{l}\text { Crown fracture } \\
\text { with pulp involvement }\end{array}$ & $\mathbf{2 2 0}$ & 100 \\
Total & & &
\end{tabular}

involvement and $7.73 \%$ were crown fracture with pulp involvement. Table III shows that the over jet of more than 3 $\mathrm{mm}$ have an increased risk of sustaining traumatic injury to teeth $(64.4 \%)$. The common cause of fracture being sports related injury followed by falls, pushing, fighting, road accidents and unknown. Males $45(37.5 \%)$ had more fractures than females 8 (20\%) due to sports related injuries as depicted in Table IV. The risk of trauma was greater in outdoors than indoor in both the age groups. The graph I shows that the anterior teeth fracture were significantly more in full cusp antero posterior molar relation than in normal occlusion and half cusp molar relation (chi square value $=15.51$ ). Graph II depicts the prevalence of malocclusion in the fractured individuals (prevalence $-27.3 \%, \mathrm{p}<0.001$ ). Graph III, shows

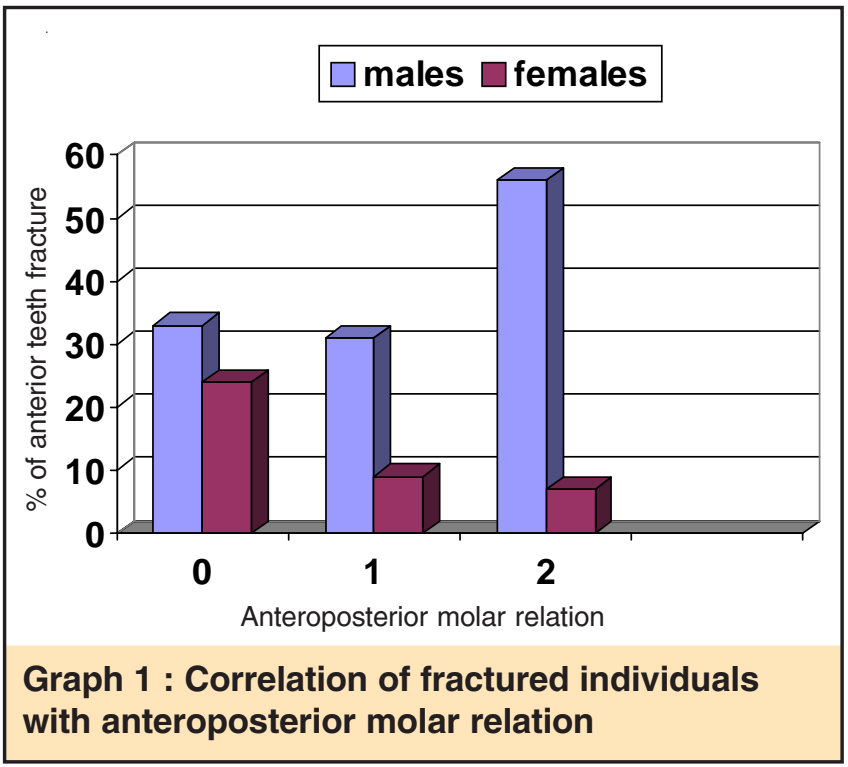

Table 3: Relation of anterior tooth fractures with anterior maxillary over jet

\begin{tabular}{|lccc|} 
& $\begin{array}{c}\text { No (and \%) } \\
\text { with injury } \\
\mathbf{n}=160\end{array}$ & $\begin{array}{c}\text { No (and \%) } \\
\text { without injury } \\
\text { injury. } \mathbf{n}=3461\end{array}$ & \\
$\begin{array}{l}\text { Normal over jet } \\
\text { Increased incisor }\end{array}$ & $57(35.6 \%)$ & $3119(90.1 \%)$ & 3176 \\
over jet $(>3 \mathrm{~mm})$ & $103(64.4 \%)$ & $342(9.9 \%)$ & 445 \\
\hline
\end{tabular}

the spacing, crowding were more common in one segment, diastema was seen more in 12 yrs $(14.39 \%)$ age group as compared to $15 \mathrm{yrs}(10.33 \%)$, largest anterior maxillary irregularity were common in 12 yrs $(9.09 \%)$ were as largest anterior mandibular irregularity were more common in $15 \mathrm{yrs}$ $(15.09 \%)$. Anterior maxillary and mandibular over jet were more common in 12 yrs age group.

\section{DISCUSSION}

In the final decade of this century, dental diseases and traumatic injuries remains an unresolved problem affecting the school going children throughout the world. As we know Hindsight explains the injury that foresight would have prevented, therefore a study was carried out to know the prevalence of anterior tooth fracture in school going children of Belgaum city as no other studies were reported previously.

The data on the prevalence of anterior teeth fracture from previous studies vary from $1.76 \%$ (8) to $46 \%$.(2) Many studies

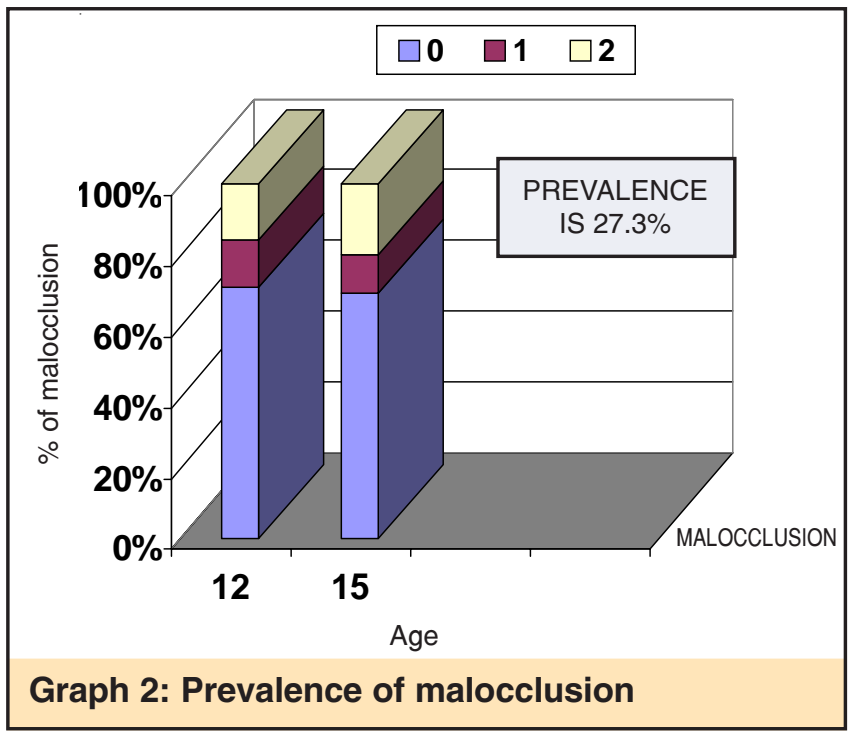

Table 4: Relation of fractures to cause and place of trauma

\begin{tabular}{lcccccccc} 
& \multicolumn{4}{c}{ CAUSE OF TRAUMA } & \multicolumn{2}{c|}{ PLACE OF TRAUMA } \\
\cline { 2 - 8 } & Falls & $\begin{array}{c}\text { Pushing and } \\
\text { fighting }\end{array}$ & Sports & $\begin{array}{c}\text { Road } \\
\text { accidents }\end{array}$ & Unknown & Outdoor Indoor & Unknown \\
No. Of teeth fractured & 35 & 28 & 53 & 23 & 23 & 77 & 60 & 23 \\
\% Of teeth fractured & 47.5 & 4 & 5 & 27.5 & 27.5 & 102 & 70 \\
\hline
\end{tabular}




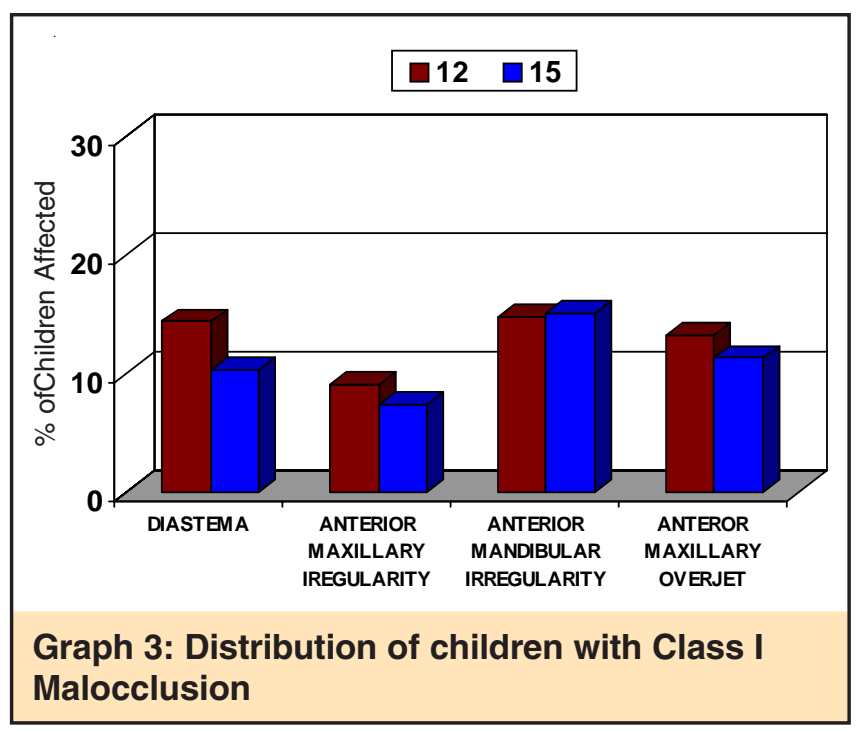

have reported prevalence rate of $20.26 \%, 35 \%$ and $8.7 \%$ $(9,10,11)$ In our study the prevalence rate of fractured anterior teeth was $4.41 \%$ which was similar to a study conducted by Zerman N and Cavalleri G. in 1993.(12) In the present study, the prevalence of anterior teeth fracture was more in boys, as more boys are engaged in rough outdoor games than girls. Our results were in concurrence with the many study reports. $(13,14,15)$ Were as some studies, have reported not much difference in the prevalence of boys and girls. $(2,8,11,16,17)$

We observed that 12-year age group had more fractures (7.14\%) when compared to 15 years age group $(5.03 \%)$ the observation was in contrast to some studies. $(10,13)$ Central incisors were most commonly affected $(83.2 \%)$ than other anterior teeth. The reasons being its vulnerable position in the oral cavity, frequent protrusion of incisors or inadequate lip coverage hence reduced cushioning effect. It was observed that sports related injury was more common followed by falls, pushing and fighting, and road accidents. Males (37.5\%) were affected more than females (20\%) in sports related injuries and the results were in concurrence with other study reports. $(4,9,13)$ In classrooms, teachers supervise the children and their activity is relatively controlled; moreover, children spend most of their time outside and falls could result from a variety of conditions. Therefore the risk of trauma was greater in outdoors than indoor in both the age groups. Mouth guards should be encouraged and made compulsory in all contact sports and, children should be taught what should be done with avulsed tooth.

In our study the frequency of traumatic injuries to permanent upper incisors increased in relation to the increasing over jet. An over jet greater than normal thus creates an obvious risk for injuries. The incidence of anterior teeth fracture increased with antero posterior molar relationship, which is statistically significant $(\mathrm{P}<0.001)$. Similar results were obtained by other studies. $(8,19)$

In conclusion, the dental injuries are frequently occurring during the different stages of life but they are particularly common in childhood (in the present study the age group more prone for injuries is 12 years). There is a strong relationship between malocclusion and fractured anterior teeth and over jet of more than $3 \mathrm{~mm}$ have an increased risk of sustaining traumatic injury to their incisors.

\section{ACKNOWLEDGEMENT}

My sincere regards to Mr., Prabhakar. Kore, chairman, KLE'S society Belgaum, for all the support and continuous guidance. I will be failing in duty if I don't thank the study subjects, authorities and Dr. Aswini , postgraduate student, Dept. of Preventive and Community Dentistry, KLE'S Institute of Dental Sciences, Belgaum who have helped me in this study.

\section{THE AUTHOR}

\section{Dr. Pradeep. S. Tangade}

MDS,

Reader,

Department of Preventive and Community Dentistry

KLE'S Institute of Dental Sciences,

Belgaum-590010,

Karnataka, India.

Phone No: +918319448578170

E-Mail ID: pradeeptangade@yahoo.co.in

\section{REFERENCES}

1. Gutz D.P. Fractured permanent incisors in a clinic population. J Dent for Children 1971; 38:94-95, 98-99,121.

2. Andreasen.J.O and Ravn J.J. Epidemiology of Traumatic dental injuries to primary and permanent teeth in a Danish population sample. Int J Oral Surg 1972; 1:235-239.

3. Lewis T.E. Incidence of fractured anterior teeth as related to their protrusion. Angle Orthodontist 1959; 29:128-131.

4. Mullane DMO. Some factors predisposing to injuries of permanent incisors in school children. Br Dent J 1973; 134: 328-332.

5. Dunning J. M. Principles of Dental Public Health $2^{\text {nd }}$ edn, p533535. Cambridge, Mass: Harvard university press. 1970.

6. Ingle J.I, Leit K, Baklard. Traumatic dental injuries chapter $17^{\text {th }}$, endodontic Fourth edn, p765. Williams and Wilkins publications. 1994.

7. World health organization. Oral health survey basic methods. Fourth edn. Geneva. 1997.

8. Chandra. S and Chawala. T. N. Incidence of fracture of anterior teeth and their correlation with malocclusion in children. JI Ind Dent Assoc 1976; 191-198.

9. Petti $S$ and Tarsitani G. Traumatic injuries to anterior teeth in Italian school children prevalence and risk factors. Endod Dent Traumatol 1996; 12:294-297.

10. Garcia Godoy $F$ et al. Traumatic dental injuries in pre-school children from Santo Domingo. Comm Dent Oral Epidemiol 1983; 9:193-197.

11. Zadik. D, Chosack A and Eidelman E. A survey of traumatized incisors in Jerusalem school children. JI Den children 1972; 39:185188. 
12. Zerman $\mathbf{N}$ and Cavalleri G. Traumatic Injuries to Permanent Incisors. Endod Dent Traumatol 1993; 9:61-64.

13. Gauba M.L. A Correlation Of Fractured Anterior Teeth to their proclination. JI Ind Dent Assoc 1967; 39:105-112.

14. Otuyemi O.D. Traumatic dental injuries related to incisor over jet and lip competence in 12 year old Nigerian children. Int $\mathrm{JI}$ Pediat Dent 1994; 4:81-85.

15. Burton $\mathrm{J}$ et al. Traumatized anterior teeth amongst high school students in northern Sydney. Aust Dent JI. 1985; 30(5): 346-348.

16. Yagot $\mathrm{KH}$, Nazhat $\mathrm{N} Y$ and Kuder $\mathrm{S} A$. Traumatic dental injuries in nursery school children from Baghdad, Iraq. Comm Dent Oral Epidemiol. 1988; 16:292-293.

17. Macko DJ et al. A study of fractured anterior teeth in a school population. Jl of Dent Children 1979;46:130-133.

18. Stockwell AJ. Incidence of dental trauma in the western Australian school dental service. Comm Dent oral epidemiol 1988; 16: 294298.

19. Mcewen J D, Mchugh W.D AND Hitchin A.D. Fractured maxillary central incisors and incisal relationships. Jl of Dent Res 1967; 46:1290(abstract 87). 